\title{
Semireplication-competent vesicular stomatitis virus as a novel platform for oncolytic virotherapy
}

\author{
Alexander Muik • Catherine Dold • Yvonne Geiß • \\ Andreas Volk • Marina Werbizki - Ursula Dietrich • \\ Dorothee von Laer
}

Received: 26 July 2011 /Revised: 3 January 2012 / Accepted: 16 January 2012 /Published online: 28 January 2012

(C) The Author(s) 2012. This article is published with open access at Springerlink.com

\begin{abstract}
Among oncolytic viruses, the vesicular stomatitis virus (VSV) is especially potent and a highly promising agent for the treatment of cancer. But, even though effective against multiple tumor entities in preclinical animal models, replication-competent VSV exhibits inherent neurovirulence, which has so far hindered clinical development. To overcome this limitation, replication-defective VSV vectors for cancer gene therapy have been tested and proven to be safe. However, gene delivery was inefficient and only minor antitumor efficacy was observed. Here, we present semireplicationcompetent vector systems for VSV (srVSV), composed of two trans-complementing, propagation-deficient VSV vectors. The de novo generated deletion mutants of the two VSV polymerase proteins $\mathrm{P}$ (phosphoprotein) and L (large catalytic subunit), VSV $\Delta \mathrm{P}$ and $\mathrm{VSV} \Delta \mathrm{L}$ respectively, were used mutually or in combination with VSV $\Delta \mathrm{G}$ vectors. These srVSV systems copropagated in vitro and in vivo without recombinatory reversion to replication-competent virus. The srVSV systems were highly lytic for human glioblastoma cell lines, spheroids, and subcutaneous xenografts. Especially the combination of VSV $\Delta \mathrm{G} / \mathrm{VSV} \Delta \mathrm{L}$ vectors was as potent as wild-type VSV (VSV-WT) in vitro and induced long-term tumor regression in vivo without any associated adverse
\end{abstract}

Electronic supplementary material The online version of this article (doi:10.1007/s00109-012-0863-6) contains supplementary material, which is available to authorized users.

A. Muik $\cdot$ Y. Geiß A. Volk $\cdot$ M. Werbizki $\cdot$ U. Dietrich Georg-Speyer-Haus,

60596 Frankfurt am Main, Germany

C. Dold $\cdot$ D. von Laer $(\bowtie)$

Institute for Virology, Innsbruck Medical University,

Fritz-Pregl-Str. 3,

A-6020 Innsbruck, Austria

e-mail: dorothee.von-Laer@i-med.ac.at effects. In contrast, 90\% of VSV-WT-treated animals succumbed to neurological disease shortly after tumor clearance. Most importantly, even when injected into the brain, VSV $\Delta \mathrm{G} /$ VSV $\Delta \mathrm{L}$ did not show any neurotoxicity. In conclusion, srVSV is a promising platform for virotherapeutic approaches and also for VSV-based vector vaccines, combining improved safety with an increased coding capacity for therapeutic transgenes, potentially allowing for multipronged approaches.

Keywords Vesicular stomatitis virus · Oncolytic virus . Virotherapy $\cdot$ Malignant glioma

\section{Introduction}

The use of viruses as targeted cancer therapeutics has shown significant promise in the last few years. Especially the vesicular stomatitis virus (VSV), a relatively new player in the oncolytic virotherapy field, has proven to be effective against a variety of tumor entities such as malignant glioma $[1,2]$, hepatocellular carcinoma [3, 4], prostate cancer [5, 6], and ovarian carcinoma [7]. However, to date, the inherent neurotoxicity of VSV has hindered clinical development since intracerebral administration causes fatal encephalitis in rodents and nonhuman primates $[8,9]$. Thus, replicationcompetent VSV is associated with an increased risk of systemic dissemination and potentially severe pathology if it enters the CNS. Therefore, attenuated virus variants and propagation-deficient viral vectors were generated. Unfortunately, the reduced toxicity of attenuated replicationcompetent VSV is invariably accompanied with some reduction of replicative and oncolytic activity $[10,11]$, whereas the major limitation of propagation-deficient viral vectors has been the inefficient transduction rate of cancer cells in vivo $[2,12]$. 
A new strategy to potentially enhance safety of replicationcompetent VSV while increasing the capacity for therapeutic transgenes is the use of a semireplication-competent vector system similar to those described for retroviruses and adenoviruses $[13,14]$. Here, we successfully developed a semireplication-competent vector system for VSV (srVSV), which is based on two trans-complementing propagation-deficient VSV vectors. The genes essential for viral replication are divided onto two separate packageable vector genomes, so that infectious progeny can only be produced in double-infected host cells. Importantly, the VSV RNA genome does not undergo genetic reassortment or recombination, making it unlikely that the binary system reverts into a replication-competent recombinant VSV [15]. In this study, we used the propagation-deficient, eGFPexpressing $\mathrm{VSV}^{*} \Delta \mathrm{G}$-vector [16], which lacks the $\mathrm{G}$ gene, in combination with de novo synthesized and rescued deletion mutants VSV $\Delta$ P-DsRed and VSV $\Delta$ L-DsRed, lacking the genes $\mathrm{P}$ and $\mathrm{L}$, respectively, that encode the components of the viral polymerase complex. Accordingly, three different srVSV combinations were feasible: $\mathrm{VSV}^{*} \Delta \mathrm{G} / \mathrm{VSV} \Delta \mathrm{P}-\mathrm{DsRed}(\operatorname{srVSV}(\Delta \mathrm{G} / \Delta \mathrm{P})), \mathrm{VSV}^{*} \Delta \mathrm{G} /$ VSV $\Delta \mathrm{L}-\mathrm{DsRed}(\operatorname{srVSV}(\Delta \mathrm{G} / \Delta \mathrm{L}))$, and VSV $\Delta \mathrm{P}$-DsRed $/$ $\operatorname{VSV} \Delta \mathrm{L}-\mathrm{DsRed}(\operatorname{srVSV}(\Delta \mathrm{P} / \Delta \mathrm{L}))$. All srVSV systems allowed for in vitro reciprocal complementation thus leading to copropagation associated with clear antitumor potency against human glioblastoma cell lines. In addition, the most potent vector combination, $\operatorname{srVSV}(\Delta \mathrm{G} / \Delta \mathrm{L})$, was tested in a preclinical subcutaneous (s.c.) glioblastoma mouse model and proved to be only slightly attenuated compared to wild-type VSV (VSV-WT). Tumors regressed in both cohorts, but in contrast to the srVSV-treated group, $90 \%$ of VSV-WT-treated animals succumbed to viral neurotoxicity. Most importantly, neither srVSV treatment of tumorbearing animals nor direct intracranial administration in healthy mice was associated with any sign of neurotoxicity. Eventually, all srVSV systems proved to be safe as we have not been able to detect any sign of recombinatory reversion to the wild-type strain.

\section{Materials and methods}

\section{Cell culture}

BHK-21 baby hamster kidney and U-87 MG human glioblastoma cells were obtained from the American Type Culture Collection (Manassas, VA). G62 human glioblastoma cells were kindly provided by M. Westphal (University Hospital Eppendorf, Hamburg, Germany). HEK 293-NPeGFPL (clone 206) stably expressing VSV-N, P, and L protein were a gift from A. Pattnaik (University of Nebraska, Lincoln, USA) [17]. All cells were kept in a humidified atmosphere containing 5\%
$\mathrm{CO}_{2}$ at $37^{\circ} \mathrm{C} . \mathrm{BHK}-21, \mathrm{U}-87 \mathrm{MG}, \mathrm{G} 62$, and 293-NPeGFPL cells were maintained in DMEM (Gibco) supplemented with 10\% FBS (Perbio Science). 293-NPeGFPL cells were kept under G418 selection.

\section{Viruses}

The propagation-incompetent $\mathrm{VSV}^{*} \Delta \mathrm{G}$ vector, coding for eGFP as reporter, as well as the particularly strong type I interferon (IFN) inducing $\mathrm{VSV}^{*} \mathrm{M}_{\mathrm{Q}}$, a replicationcompetent VSV with multimutated matrix protein (VSV$\mathrm{M})$, have been described previously $[16,18]$. The deletion mutants VSV $\Delta \mathrm{P}$-DsRed and VSV $\Delta \mathrm{L}$-DsRed were generated de novo: To exchange the VSV-P gene for DsRed, the N$\mathrm{P}$ intergenic region (IGR) and a part of the VSV-N gene as well as the P-M IGR and a part of the M gene were PCR amplified from pVSV-XN2 using the primers $5{ }^{\prime}$-CGATC TCGAGGTATACATCTCTTACTACAGCAGG-3' $/$ ' $^{\prime}$ CAGTGAATTCGATATCTGTTAGTTTTTTTCATATG TAGC-3' (N-P IGR) and 5'-CGATGCGGCCGCACTAT GAAAAAAAGTAACAGATATCACG-3'/5'-CAGTCCGC GGACGCGTAAACAGATCGATCTCTG-3' (P-M IGR) with unique restriction sites (shown in bold). In parallel, DsRed was subcloned from pDsRed-Express-N1 (Clontech) into the multiple cloning site (MCS) of the pBluescript-II cloning vector (Stratagene) with BamHI/NotI. Subsequently, PCR products were digested with $X h o I / E c o R I$ (N-P IGR) and NotI/SacII (P-M IGR) and sequentially cloned in front and behind the DsRed gene. Finally, the DsRed cassette was excised with BstZ17i/MluI and inserted into the BstZ17i/ MluI site of pVSV-XN2, replacing VSV-P to yield $\mathrm{pVSV} \Delta \mathrm{P}$-DsRed. A similar cloning strategy was applied to generate $\mathrm{pVSV} \Delta \mathrm{L}$-DsRed: The G-L IGR and a part of the VSV-G gene as well as the L-HDV ribozyme region were PCR amplified from pVSV-XN2 using the primers 5'CAGTGGTACCCTAAAATACTTTGAGACCAG-3'/5'C G A T G G A T C C G A T T G C T G T T A G T T T T T T TCATAAAAATTAAAAACTC-3' (G-L IGR) and 5'CAGTGCGGCCGCAAAATCATGAGGAGACTC CAAACTTTAAG-3'/5'-CGATGAGCTCGCACTAG TATCGAGGTCTCGATC-3' (L-HDV ribozyme) with unique restriction sites (shown in bold). PCR products were digested with KpnI/BamHI (G-L IGR) and NotI/SacI (L-HDV ribozyme) and cloned in front and behind the DsRed gene in the pBluescript-II-DsRed vector. Finally, DsRed was excised with NheI/SpeI and inserted into the NheI/SpeI site of pVSV-XN2, yielding pVSV $\Delta$ L-DsRed. Novel recombinant viruses (Fig. 1a) were rescued as described previously [19]. To produce infectious virions, $\mathrm{VSV}^{*} \Delta \mathrm{G}$-vectors were propagated on BHK-21 cells transiently expressing VSV-G [20]. VSV $\Delta$ P-DsRed and VSV $\Delta$ L-DsRed were amplified on 293-NPeGFPL cells. Vector titers were determined as $50 \%$ tissue culture infective dose $\left(\mathrm{TCID}_{50}\right)$ using the 

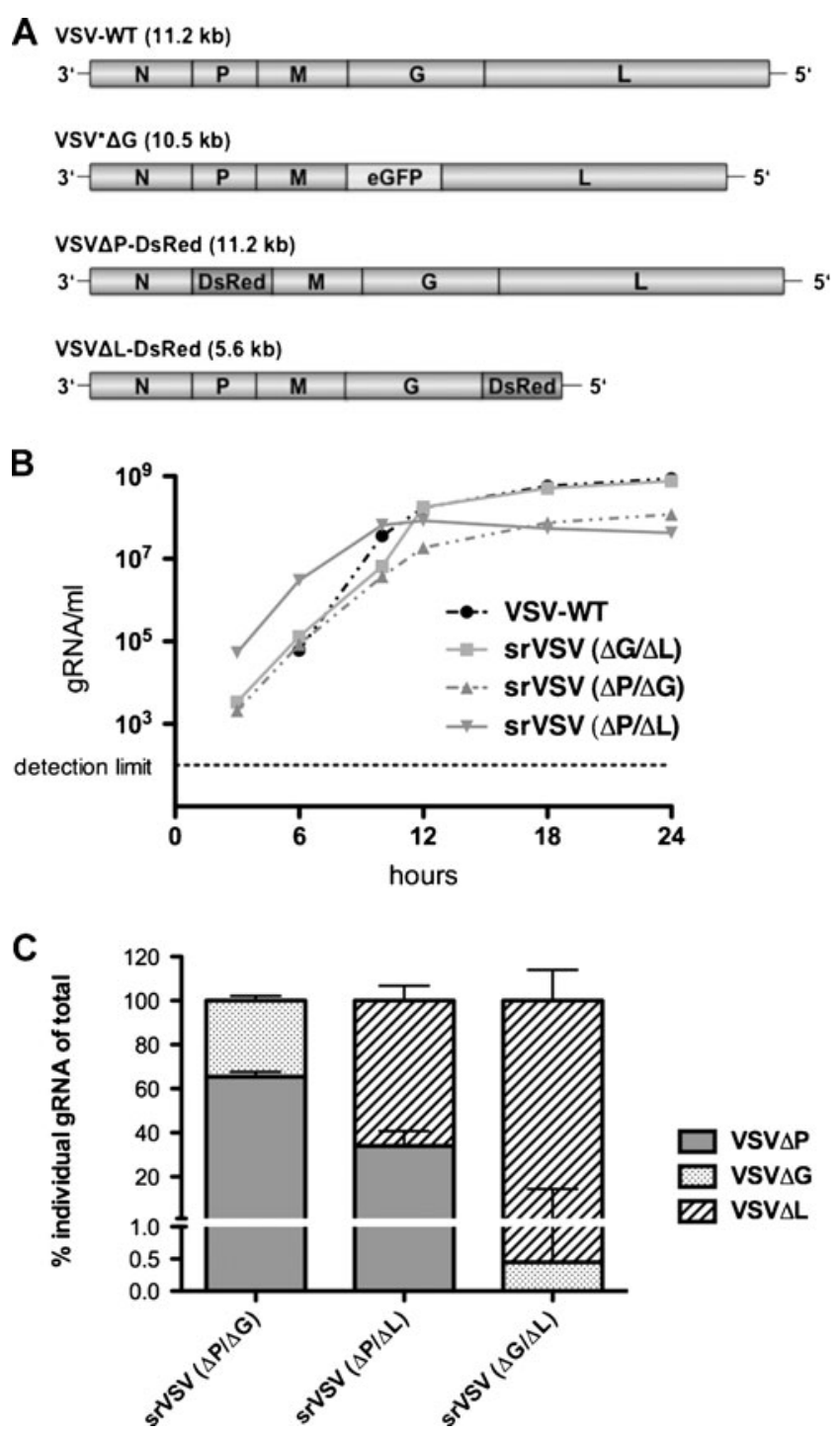

Fig. 1 Construction and functional characterization of srVSV systems. a Schematic representation of the recombinant vesicular stomatitis virus $(V S V)$ genomes. Genomes and the respective open reading frames are presented in $3^{\prime}-5^{\prime}$ orientation. b Multicycle growth curves of srVSV systems compared to VSV-WT. BHK-21 cells were infected with VSVWT or the respective srVSV systems at an MOI of 0.05 . At the indicated time points postinfection, culture supernatants were collected and viral genomic RNA was determined by real-time RT-PCR. Virus titers of $n=2$ infection experiments are shown as mean \pm SD. c Symmetry of individual vector genome contributions during copropagation was assessed via realtime RT-PCR using two independent primer/probe sets. Ratios of individual vector titers per total vector concentration are shown as mean $\pm \mathrm{SD}$

Spearman-Kärber method [21]. VSV $\Delta$ P-DsRed and VSV $\Delta$ L-DsRed titration was performed on 293-NPeGFPL cells, VSV-WT and VSV* $\mathrm{M}_{\mathrm{Q}}$ were titrated on BHK-21 cells, and $\mathrm{VSV}^{*} \Delta \mathrm{G}$ titration was performed on BHK-GP [20].

Quantitative PCR-based multicycle growth curve analysis

BHK-21 cells were infected in 6-well plates $\left(10^{6}\right.$ cells/well $)$ with a multiplicity of infection (MOI) of 0.05 of each individual vector of the three potential srVSV vector systems or VSV-WT as positive control. Filtered $(0.45 \mu \mathrm{m})$ supernatants were collected at the indicated time points, and RNA was extracted from $50 \mu$ l supernatant using the RNeasy Mini Kit (Qiagen). RNA was reverse transcribed using the High Capacity RNA-to-cDNA Kit (Applied Biosystems). Vector propagation was monitored via real-time RT-PCR to determine the total VSV genomic RNA (gRNA) amount in supernatants [19]. Known plasmid amounts were used to determine the standard curve for real-time RNA quantification. Two independent qPCR primer and probe sets were used, spanning the N-P and the M-G IGR of the VSV genome (see Supplementary Fig. S1c, d). Real-time PCR was carried out with the TaqMan ${ }^{\circledR}$ Gene Expression Master Mix (Applied Biosystems) using a LightCycler ${ }^{\circledR}$ 480 Real-Time PCR System (Roche). For both applied real-time PCRs, the detection limit was $10^{2} \mathrm{gRNA} / \mathrm{ml}$.

In vitro cytotoxicity assay

Human glioblastoma cells were plated in 96-well plates at $10^{4}$ cells/well in $100 \mu \mathrm{l}$ medium. Cells were cultured as monolayer or multicellular tumor spheroids. For spheroid cultures, 96-well plates were precoated with $75 \mu 11 \%$ agar noble (Difco). Cultures were infected with the respective viral system (srVSV or VSV-WT) at an MOI of 0.2 or treated with phosphate-buffered saline (PBS) the following day. Cell viability was assayed in dodecaplicates in $n=3$ independent experiments at the indicated time points postinfection using the cell proliferation agent WST-1 (Roche). Results are expressed as percentage of viable cells compared to PBS-treated controls.

Animal studies

For antitumor efficacy testing, 6-week old NOD/SCID mice (Jackson Laboratories) were anesthetized with isoflurane and $10^{6}$ G62 human glioblastoma cells were subcutaneously injected into the left and right flanks. Tumor growth was monitored with a caliper. At a tumor volume of $0.1 \mathrm{~cm}^{3}$, mice were treated intratumorally with two doses of either $2.8 \times 10^{5}$ $\operatorname{TCID}_{50} \operatorname{srVSV}(\Delta \mathrm{G} / \Delta \mathrm{L})$ or $2.8 \times 10^{5} \mathrm{TCID}_{50} \mathrm{VSV}-\mathrm{WT}$ and PBS as controls. Bilateral tumors were treated alike. When tumor size exceeded $0.8 \mathrm{~cm}^{3}$, mice were sacrificed. In addition, two mice were sacrificed at 3 days post-srVSV treatment and s.c. tumors were prepared for immunofluorescence analysis.

For neurotoxicity analysis, 6-week old CD1 Swiss mice (Charles River) were anesthetized by intraperitoneal injection of ketamine/xylazine (100 and $10 \mathrm{mg} / \mathrm{kg}$ of body weight, respectively). $10^{2}, 10^{3}$, and $10^{4} \operatorname{TCID}_{50} \operatorname{srVSV}(\Delta \mathrm{G} / \Delta \mathrm{L})$, as well as $1.4 \times 10^{1}$ and $1.4 \times 10^{4} \mathrm{TCID}_{50}$ VSV-WT or PBS were stereotactically injected into the right frontal lobe of mice brains $(1.5 \mathrm{~mm}$ lateral, $2 \mathrm{~mm}$ rostral to the bregma at $2 \mathrm{~mm}$ 
depth). Animals were monitored for signs of neurological impairment. Two mice of the $10^{4} \operatorname{TCID}_{50} \operatorname{srVSV}(\Delta \mathrm{G} / \Delta \mathrm{L})$ treated group were sacrificed at 3 days postinjection (dpi), and brains were prepared for immunofluorescence analysis. The brains were sectioned $(40 \mu \mathrm{m})$ on a Leica VT1000S vibratome (Leica, Bensheim, Germany). Nuclear counterstaining was performed with TO-PRO-3 iodide (Invitrogen). Sections were analyzed by confocal laser scanning microscopy using a Nikon C1S1 microscope (Nikon, Düsseldorf, Germany). All procedures were approved by the governmental board for the care of animal subjects (Regierungspräsidium Darmstadt, Germany).

Stimulation and IFN- $\alpha$ detection

Murine bone marrow (BM)-derived plasmacytoid dendritic cells (pDCs) were generated as previously described [22]. In brief, BM cells were flushed from femur and tibia with RPMI supplemented with 10\% FBS (Perbio Science). Erythrocytes were lysed, cells were washed, and single-cell suspensions were cultivated for 8 days in medium supplemented with $100 \mathrm{ng} / \mathrm{ml} \mathrm{Flt3-L} \mathrm{(R \& D} \mathrm{Systems).} \mathrm{As} \mathrm{determined} \mathrm{by} \mathrm{FACS}$ analysis, Flt3-L cultures consisted of $\approx 20 \% \mathrm{CD} 11 \mathrm{c}^{+} \mathrm{B} 220^{+}$ pDCs (data not shown). For IFN stimulation experiments, $2 \times 10^{6}$ Flt3-L-stimulated BM-pDC bulk culture cells were seeded per 24 well. Cultures were infected with either srVSV, VSV $* \Delta \mathrm{G}, \mathrm{VSV} \Delta \mathrm{L}-\mathrm{DsRed}, \mathrm{VSV}-\mathrm{WT}$, or VSV $* \mathrm{M}_{\mathrm{Q}}$ (each $n=$ 2 ) at an MOI of 2 . Supernatants were collected at $24 \mathrm{~h}$ postinfection (hpi) and analyzed for IFN- $\alpha$ via ELISA (PBL Biomedical Laboratories).

\section{Statistical analysis}

For comparison of individual time points or columns, statistical difference was determined using unpaired $t$ test. Mice survival curves were plotted as Kaplan-Meier analysis, and statistical significance between treatment groups was compared using the log-rank test.

\section{Results}

Novel recombinant viruses were cloned based on the pVSV$\mathrm{XN} 2$ plasmid background and rescued as described previously [19]. A schematic representation of the VSV vector genomes is shown in Fig. 1a, and their identity was confirmed by gene-specific RT-PCR (Supplementary Fig. S1a, b). Both deletion mutants, VSV $\Delta$ P-DsRed and VSV $\Delta$ LDsRed, were unable to propagate and did not generate progeny virions in cell cultures not providing the respective deleted viral gene in trans, as real-time RT-PCR (Supplementary Fig. S1c, d) of supernatants were negative for VSV gRNA (data not shown).
$\operatorname{srVSV}(\Delta G / \Delta L)$ is the most potent srVSV system in terms of vector propagation In order to assess the replication competence of the three potential srVSV systems, BHK-21 cells were infected with an MOI of 0.05 of each individual vector or VSV-WT as control to generate multicycle growth curves. Vector propagation was monitored on the gRNA level via real-time RT-PCR [19]. In VSV-WT-infected cultures, gRNA associated with secreted progeny virions was first detectable at $6 \mathrm{hpi}$, reaching a plateau around 12-18 hpi with maximum titers of more than $8 \times 10^{8} \mathrm{gRNA} / \mathrm{ml}(8.77 \times$ $10^{8} \pm 9.28 \times 10^{7} \mathrm{gRNA} / \mathrm{ml}$, see Fig. $1 \mathrm{~b}$ ). In comparison, all srVSV vector systems showed an earlier onset of replication with first gRNA detectable at $3 \mathrm{hpi}$ and $\operatorname{srVSV}(\Delta \mathrm{P} / \Delta \mathrm{L})$ being the most potent in the initial phase with titers of $5.33 \times$ $10^{4} \pm 3.05 \times 10^{3} \mathrm{gRNA} / \mathrm{ml} 3 \mathrm{hpi}$. Both, the $\operatorname{srVSV}(\Delta \mathrm{P} / \Delta \mathrm{G})$ and the $\operatorname{srVSV}(\Delta \mathrm{G} / \Delta \mathrm{L})$ system lagged behind with titers being about tenfold reduced 3-6 hpi. Consistently, srVSV $(\Delta \mathrm{P} / \Delta \mathrm{L})$ was also the first to reach its plateau at $10-12 \mathrm{hpi}$ with a maximum of $8.44 \times 10^{7} \pm 3.63 \times 10^{6} \mathrm{gRNA} / \mathrm{ml}$ before its titer slowly started to regress. In contrast, both srVSV $(\Delta \mathrm{P} / \Delta \mathrm{G})$ and $\operatorname{srVSV}(\Delta \mathrm{G} / \Delta \mathrm{L})$ ended up with a more robust replication, reaching titers of $1.19 \times 10^{8} \pm 1.63 \times 10^{6} \mathrm{gRNA} /$ $\mathrm{ml}$ for $\operatorname{srVSV}(\Delta \mathrm{P} / \Delta \mathrm{G})$ and $7.60 \times 10^{8} \pm 4.47 \times 10^{7} \mathrm{gRNA} / \mathrm{ml}$ for $\operatorname{srVSV}(\Delta \mathrm{G} / \Delta \mathrm{L})$ at $24 \mathrm{hpi}$. Thus, the binary system using $\mathrm{VSV}^{*} \Delta \mathrm{G}$ and VSV $\Delta \mathrm{L}-\mathrm{DsRed}$ was the most potent srVSV system in terms of vector dissemination even reaching maximum gRNA titers comparable to VSV-WT.

In parallel, srVSV functional titers of supernatants collected at 24 hpi were determined as TCID $_{50}$ per milliliter, as double-infected cells are a prerequisite to initiate copropagation. Correspondingly, the $\mathrm{TCID}_{50}$ of srVSV systems were $180-(\operatorname{srVSV}(\Delta \mathrm{G} / \Delta \mathrm{L}))$ to 2,000 -fold $(\operatorname{srVSV}(\Delta \mathrm{P} /$ $\Delta \mathrm{L})$ ) lower than their gRNA titers, primarily reflecting the chance of coinfection, and to a considerably lesser extent reflecting the difference between genome and functional titers, as VSV-WT gRNA titers were only 6-fold higher compared to the respective $\mathrm{TCID}_{50}$. However, consistent with the maximum obtained VSV gRNA per milliliter concentrations during the multicycle growth curve, $\operatorname{srVSV}(\Delta \mathrm{G} /$ $\Delta \mathrm{L}$ ) displayed the highest $\mathrm{TCID}_{50}$ per milliliter of $4.22 \times$ $10^{6}$, whereas titers for $\operatorname{srVSV}(\Delta \mathrm{P} / \Delta \mathrm{G})$ were approx. 20-fold and for $\operatorname{srVSV}(\Delta \mathrm{P} / \Delta \mathrm{L})$ around 100 -fold lower (Table 1).

srVSV systems are characterized by asymmetric copropagation As srVSV systems are composed of two vectors with

Table 1 Functional titers

\begin{tabular}{ll}
\hline Viral system & $\mathrm{TCID}_{50} / \mathrm{ml}$ \\
\hline $\operatorname{VSV}-\mathrm{WT}$ & $1.58 \times 10^{8}$ \\
$\operatorname{srVSV}(\Delta \mathrm{G} / \Delta \mathrm{L})$ & $4.22 \times 10^{6}$ \\
$\operatorname{srVSV}(\Delta \mathrm{P} / \Delta \mathrm{G})$ & $2.37 \times 10^{5}$ \\
$\operatorname{srVSV}(\Delta \mathrm{P} / \Delta \mathrm{L})$ & $4.22 \times 10^{4}$ \\
\hline
\end{tabular}


different properties such as gene composition and genome size, the mode of copropagation during the multicycle growth curve was analyzed via two independent qPCRs with amplicons spanning the N-P or M-G IGR of the VSV genome (Supplementary Fig. S1c, d). Combining the obtained qPCR data, single-vector titers were calculated as ratio of the individual vector gRNA per milliliter per total vector gRNA per milliliter for all time points of the multicycle growth curve. As ratios proved to be consistent for each srVSV system throughout the whole observation period of $24 \mathrm{~h}$, time-independent means and standard deviations were calculated. Indeed, the assessment revealed that vector copropagation was not due to symmetric replication of both vector genomes, but could rather be characterized as an asymmetric process (Fig. 1c). Each srVSV system could be defined by a distinct preference of one vector over the other. In case of $\operatorname{srVSV}(\Delta \mathrm{P} / \Delta \mathrm{G})$, the $\mathrm{VSV} \Delta \mathrm{P}$ vector accounts for $65.49 \pm 2.16 \%$ and $\mathrm{VSV} \Delta \mathrm{G}$ for $34.51 \pm 2.16 \%$ of the total titer. Even more pronounced is the asymmetry in favor of the VSV $\Delta \mathrm{L}$ vector with a share of $65.99 \pm 6.78 \%(\Delta \mathrm{P} / \Delta \mathrm{L})$ and $99.55 \pm 14.03 \%(\Delta \mathrm{G} / \Delta \mathrm{L})$ of the total progeny generated.

A

$\operatorname{srVSV}(\Delta G / \Delta L)$

\section{Brightfield} eGFP
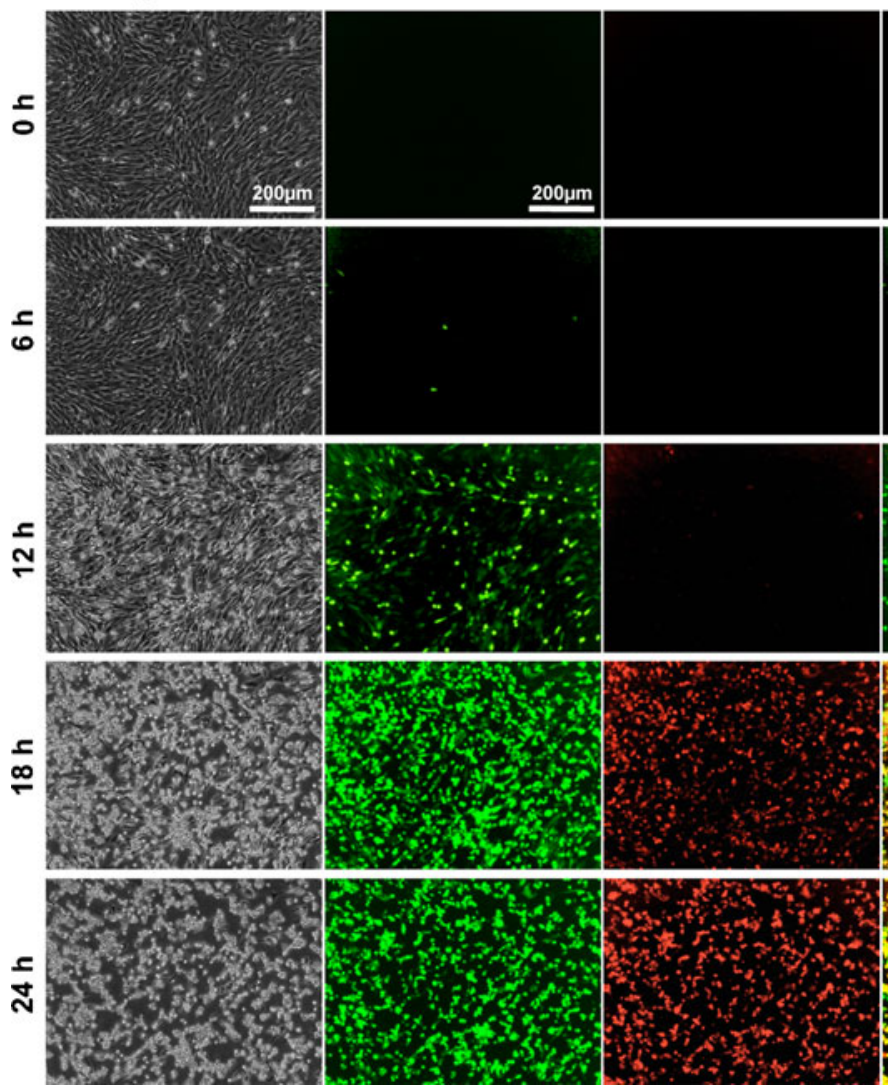

Fig. 2 Copropagation of $\operatorname{srVSV}(\Delta \mathrm{G} / \Delta \mathrm{L})$ in vitro. BHK-21 cells were infected with either a both defective VSV vectors or b only VSV* $\mathrm{V}^{*}$ at an MOI of 0.05 and monitored by fluorescence time lapse
Time lapse fluorescence microscopy of $\operatorname{srVSV}(\Delta G / \Delta L)$ copropagation In a separate experiment, $\operatorname{srVSV}(\Delta \mathrm{G} / \Delta \mathrm{L})$ copropagation was monitored by fluorescence time lapse microscopy over a period of $24 \mathrm{~h}$ after infecting BHK-21 cells at an MOI of 0.05 (Supplementary Video S1). As negative control, BHK-21 cells were infected with VSV* $\Delta$ G only. Representative micrographs at $0,6,12,18$, and 24 hpi are shown in Fig. 2. First eGFP fluorescence was detectable at 6 hpi, whereas both, DsRed-fluorescence and cytopathic effects (CPE), were confined to the srVSV-treated culture and were not detectable prior to $12 \mathrm{hpi}$ (Fig. 2a). The dissemination of the srVSV system could be tracked by a gradual increase in $\mathrm{eGFP}^{+} / \mathrm{DsRed}^{+}$cells as well as progressing CPE reaching a maximum at $24 \mathrm{hpi}$. In contrast, single-vector infected cultures did not show any propagation with only single-infected eGFP ${ }^{+}$ cells detectable throughout the observation period (see Fig. 2b and Supplementary Video S2).

srVSV shows no sign of recombinatory reversion to replication competence The main idea to develop srVSV for oncolytic virotherapy is to increase the integral safety compared to the

\section{B VSVAG-gfp alone}

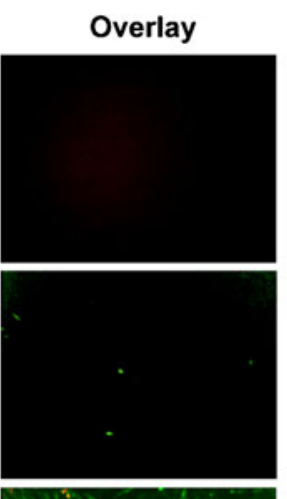

Brightfield
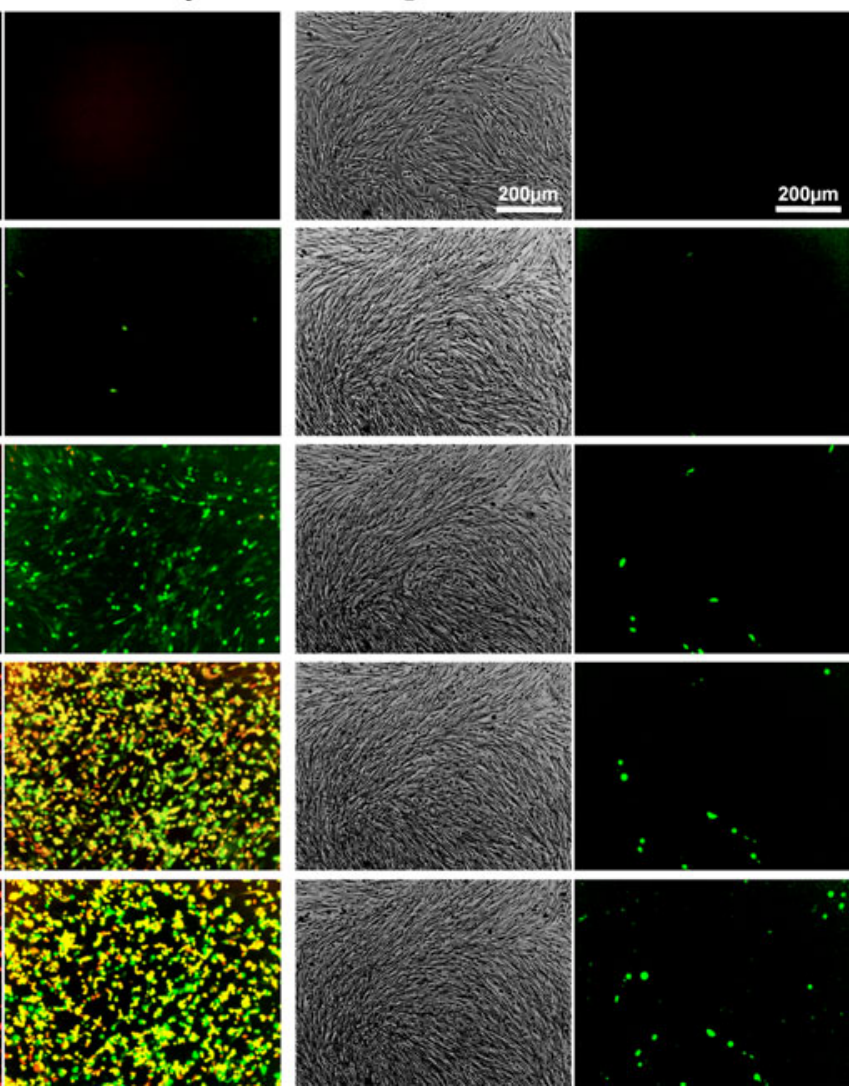

microscopy for $24 \mathrm{~h}$. Representative micrographs taken at the indicated time points are shown (time lapse movies are published as Supplementary Videos S1 and S2) 
replication-competent counterpart. Accordingly, genomic stability is an absolute requirement so that a recombinatory reversion of the binary system, potentially restoring full replicative capacity, can be precluded. In order to study viral genome stability, srVSV systems were subjected to end point dilution passage on BHK-21 cells to enable enrichment of potential functional revertants analogous to Taucher et al. [23]. To test this experimental setup, the srVSV systems were spiked with ten TCID $_{50}$ VSV-WT as internal control to see whether the replication-competent virus can selectively be enriched. Already after passage 2 for srVSV $(\Delta \mathrm{P} / \Delta \mathrm{L})$, passage 3 for $\operatorname{srVSV}(\Delta \mathrm{P} / \Delta \mathrm{G})$, and passage 4 at limiting dilutions for $\operatorname{srVSV}(\Delta \mathrm{G} / \Delta \mathrm{L})$, the control-treated BHK-21 cells showed virus-induced CPE at low supernatant concentrations (down to $10^{-7}$ ) without any fluorescence detectable. In comparison, the unspiked srVSV vector systems copropagated only at high supernatant concentrations (down to $10^{-4}$ ), whereas only single-positive cells were found in cultures treated with low concentrations (down to $10^{-6}$ ). After 20 consecutive passages, serial dilutions of srVSV supernatants were tested for the number of focus-forming units via plaque assay on BHK-21 cells. All srVSV systems formed $\mathrm{eGFP}^{+} / \mathrm{DsRed}^{+}$foci at high supernatant concentrations (down to $10^{-4}$ ) with its number not being directly proportional to the respective concentration. Instead, the interdependency between supernatant concentration and focus number could be characterized by a nonlinear biphasic decay with a goodness of fit of $R^{2}=0.99(\Delta \mathrm{G} / \Delta \mathrm{L}), R^{2}=0.99(\Delta \mathrm{P} / \Delta \mathrm{G})$, and $R^{2}=1.00$ $(\Delta \mathrm{P} / \Delta \mathrm{L}$, Fig. 3a), respectively. This is in absolute accordance with two individual replication-defective viral vectors constituting the copropagation-initializing unit. In comparison, the interdependency for the respective spiking controls as well as VSV-WT could be fitted by linear regression $\left(R^{2}\right.$ in between 0.99 and 1.0), as would be expected for a replicationcompetent virus.

Next, we also looked directly for potential recombination events by RT-PCR as a more sensitive means. cDNA of the 20th passage of the srVSV systems and the respective spiking controls was prepared and used to perform a nested PCR. The outer PCR selectively amplified the genome of one recombinant vector out of the binary system as the reverse primer binding site is constituted in the gene deletion of the other vector genome (Supplementary Fig. S2). For $\operatorname{srVSV}(\Delta \mathrm{G} / \Delta \mathrm{L})$ the $\mathrm{VSV}^{*} \Delta \mathrm{G}$ genome was amplified, whereas for $\operatorname{srVSV}(\Delta \mathrm{P} / \Delta \mathrm{G})$ and $\operatorname{srVSV}(\Delta \mathrm{P} / \Delta \mathrm{L})$ the VSV $\Delta \mathrm{P}$-DsRed genome was amplified. The inner VSV gene-specific PCRs then allowed us to check for potential recombination events at the locus of the actual gene
A

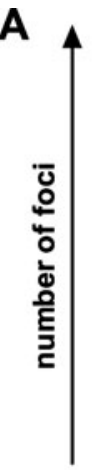

$\operatorname{srVSV}(\Delta P / \Delta G)$
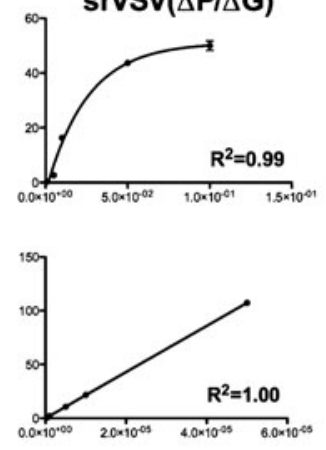

$\operatorname{srVSV}(\Delta P / \Delta L)$
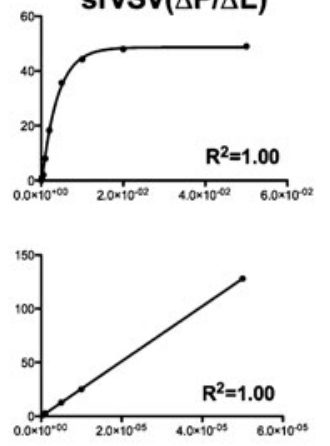

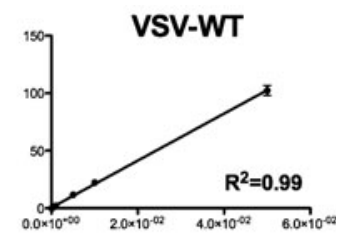

fold concentrated supernatant

B outer PCR
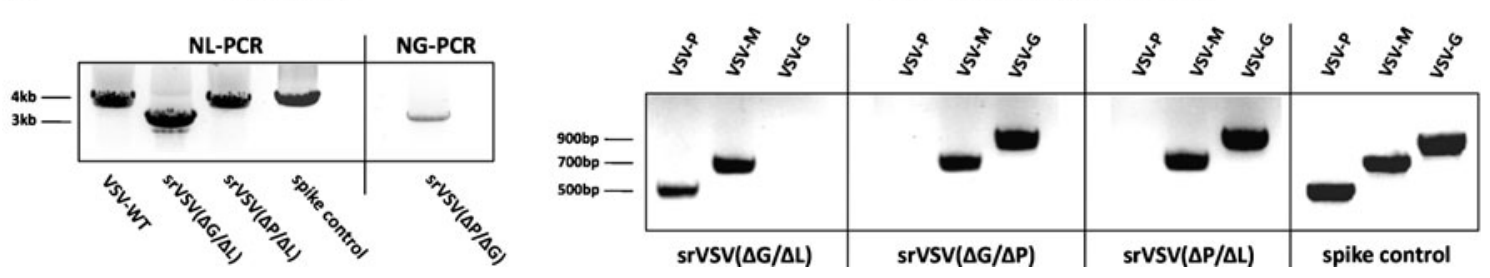

Fig. 3 srVSV systems did not revert to full replication competence after 20 consecutive passages at limiting dilutions. srVSV vector pairs were subjected to repeated passaging ( 20 passages) on BHK-21 cells at limiting dilutions. As positive control, srVSV systems were spiked with ten $\mathrm{TCID}_{50}$ VSV-WT. At passage 20, serial dilutions of culture supernatants were tested for recombinants via plaque assay and viral RNA was isolated and reverse transcribed. a Supernatant concentration dependence of the number of formed foci. Serial dilutions of supernatants were tested in triplicates $(n=3)$ and number of foci is shown as mean \pm SD. Data points were fitted with either linear regression for VSV-WT and spike controls or nonlinear regression (biphasic decay) for srVSV systems. b Direct testing for potential recombination was performed via VSV gene deletion specific analytical nested PCR. Agarose gel electrophoresis of the obtained amplicons is shown 
deletion. Consistent with the phenotypic analysis (Fig. 3a), we have not been able to detect any recombination event for the $\operatorname{srVSV}$ systems. The VSV-G (for $\operatorname{srVSV}(\Delta \mathrm{G} / \Delta \mathrm{L})$ ) and VSV-P gene $($ for $\operatorname{srVSV}(\Delta \mathrm{P} / \Delta \mathrm{G})$ and $\operatorname{srVSV}(\Delta \mathrm{P} / \Delta \mathrm{L}))$ were not detectable, whereas the according amplicons were detected for the spiking control (see Fig. 3b). These data were corroborated by sequence analysis of the outer PCR amplicons, which clearly evidenced presence of the respective fluorescence marker gene (data not shown). Thus, in both, the phenotypic and genotypic analysis, recombination among the vector genomes was not detectable while the respective spiking controls were positive, the latter validating the applicability of the applied assays.

srVSV exhibits antitumor activity in vitro and in vivo Since the srVSV systems are to be used therapeutically as anticancer agents, we assessed its antitumor potency against two different human glioblastoma cell lines, G62 and U87, in vitro as well as in a s.c. G62 xenograft model in vivo. G62 and U87 cells were infected at an MOI of 0.2 with the respective viral system, and cell viability was monitored compared to untreated controls using the WST-1 assay. In addition to monolayer cultures (Fig. 4a), multicellular spheroids of both cell lines were also used (Fig. 4b), as spheroids represent an appropriate in vitro simulation of solid threedimensional tumors resembling some of its regional heterogeneity also found in vivo [24, 25]. In the initial phase at 24 hpi, no significant differences in cell viability could be observed for U87 cells treated with the different viral systems. On the other hand, srVSV-treated G62 cultures showed significant differences compared to VSV-WT $(98.69 \pm 5.59 \%$ survival) initially at 24 hpi: G62 monolayers were reduced in cell viability for $\operatorname{srVSV}(\Delta \mathrm{G} / \Delta \mathrm{L})(88.97 \pm$ $3.55 \%$ survival $)$ and $\operatorname{srVSV}(\Delta \mathrm{P} / \Delta \mathrm{L})(80.25 \pm 8.87 \%$ survival, both $\mathrm{p}<0.01$; Fig. $4 \mathrm{a}$ ), whereas G62 spheroids showed increased cytopathic effects for all three srVSV systems tested relative to VSV-WT ( $p<0.01$, Fig. $4 b)$. At all other time points (48-120 hpi), infected glioma cultures showed gradual reduction of cell viability due to viral CPE. For G62 monolayer cultures, $\operatorname{srVSV}(\Delta \mathrm{G} / \Delta \mathrm{L})$ and $\operatorname{srVSV}(\Delta \mathrm{P} / \Delta \mathrm{L})$ were as potent as VSV-WT. In contrast, $\operatorname{srVSV}(\Delta \mathrm{P} / \Delta \mathrm{G})$ showed significantly reduced antitumor efficacy compared to all other viral systems $(p<0.001)$. Similar results were obtained for $\mathrm{G} 62$ spheroid cultures, with $\operatorname{srVSV}(\Delta \mathrm{P} / \Delta \mathrm{G})$ lagging behind in its cytotoxicity $(p<0.001)$ and srVSV $(\Delta \mathrm{P} / \Delta \mathrm{L})$ being the most potent closely followed by $\operatorname{srVSV}(\Delta \mathrm{G} / \Delta \mathrm{L})$. For U87 cultures, differences in cell viability between different treatment groups were not as strong:
Fig. 4 srVSV is comparable to VSV-WT with regard to its in vitro antitumor efficacy. a G62 and U87 human glioblastoma cells were infected with srVSV or VSV-WT at an MOI of 0.2. Cell viability was assayed at the indicated time points via WST-1 assay compared to untreated controls. b G62 and U87 human glioblastoma cells were grown as multicellular spheroids on agar. After spheroids had formed, cultures were infected with srVSV or VSV-

$\mathrm{WT}$ at an MOI of 0.2. Cell viability was assayed at the indicated time points via WST-1 assay compared to untreated controls. Bars show mean \pm SD of three independent experiments $(n=3)$ performed in dodecaplicates. ${ }^{*} p<0.05$, $* * p<0.01, * * * p<0.001$

\section{A}
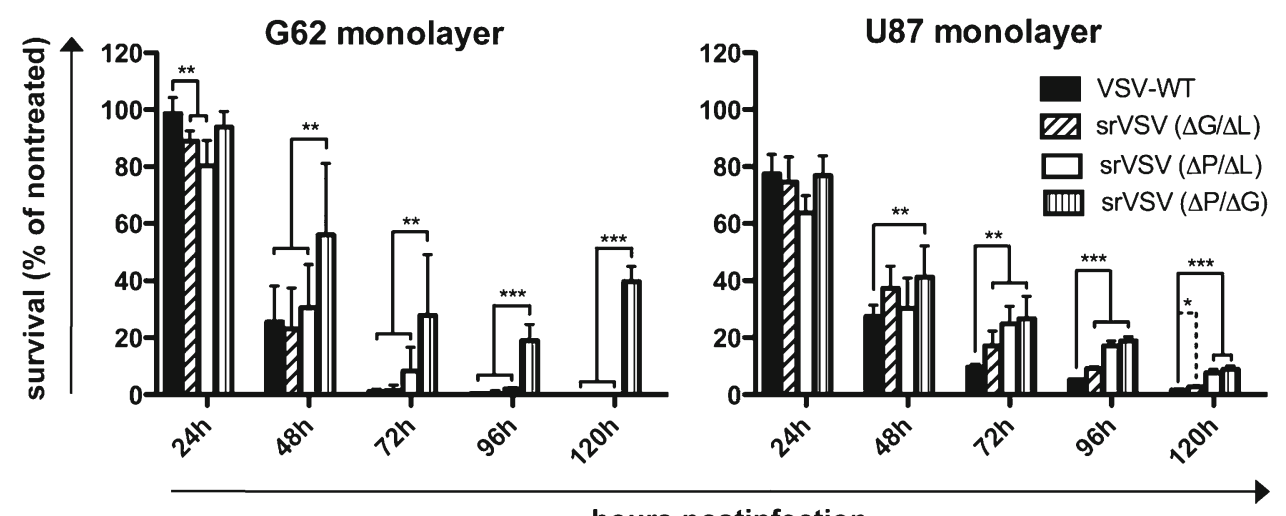

hours postinfection

B
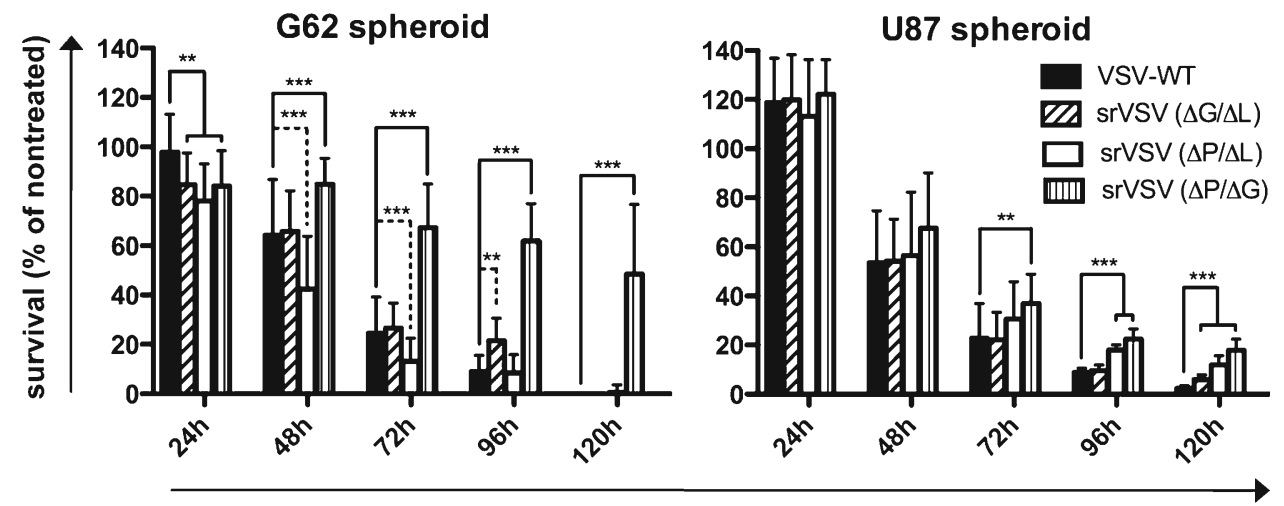

hours postinfection 
$\operatorname{srVSV}(\Delta \mathrm{P} / \Delta \mathrm{G})$-treated cultures were clearly the most viable (ranging from $p<0.01$ to $p<0.001$ ), whereas the srVSV $(\Delta \mathrm{G} / \Delta \mathrm{L})$ system performed best with regard to its antitumor effect. However, all srVSV-treated groups showed attenuated antitumor efficacy compared to VSV-WT-treated cultures.

To determine whether srVSV is also effective in vivo, the most promising $\operatorname{srVSV}$ system, $\operatorname{srVSV}(\Delta \mathrm{G} / \Delta \mathrm{L})$, was directly injected into s.c. bilateral G62 tumor xenografts at $2.8 \times 10^{5} \mathrm{TCID}_{50}$. Control tumors were either injected with PBS or $2.8 \times 10^{5} \mathrm{TCID}_{50}$ VSV-WT. PBS-treated tumors grew rapidly, and all mice had to be sacrificed before day 53 posttransplantation with a median survival of 50 days posttransplantation (dpt; Fig. 5a, c). In contrast, VSV-WTtreated mice showed a $100 \%$ tumor response rate associated with rapid reduction of tumor burden. Fourteen out of 20 (70\%) VSV-WT-injected tumors (two tumors per mouse) regressed completely, but unfortunately 9 out of $10(90 \%)$ VSV-WT-treated mice developed severe neurological symptoms (e.g., hind pawn paralysis, circulation, apathy) and had to be sacrificed, leading to a median survival of $43 \mathrm{dpt}$. Only one VSV-WT-treated mouse showed long-term event-free survival. In the srVSV-treated cohort, all tumors responded and regressed over time as well (Fig. 5a). Consistently, s.c. tumors isolated 3 days posttreatment showed multiple foci of copropagation throughout the tumor diameter (Fig. 5b). But in contrast to VSV-WT, antitumor efficacy was attenuated as tumors regressed slower with first significant differences detectable at $31 \mathrm{dpt}(p<0.001)$. However, at 80 days posttreatment $(100 \mathrm{dpt}), 16$ out of 20 tumors $(80 \%)$ were eliminated and all other tumors were continuously regressing. Most importantly, all srVSV-treated mice did not show any adverse effects, so that srVSV treatment eventually led to long-term survival compared to both control cohorts ( $p<0.0001$, Fig. 5 c).

$\operatorname{srVSV}(\Delta G / \Delta L)$ exhibits reduced neurotoxicity compared to $V S V$-WT With $\operatorname{srVSV}(\Delta \mathrm{G} / \Delta \mathrm{L})$ having shown potent antitumor activity in vitro and in vivo, its toxicity profile was evaluated after direct intracerebral administration. Mice were inoculated with either escalating doses of $10^{2}(n=3)$, $10^{3}(n=4)$, and $10^{4}(n=7) \operatorname{TCID}_{50} \operatorname{srVSV}(\Delta \mathrm{G} / \Delta \mathrm{L})$ or $1.4 \times$ $10^{1}$ and $1.4 \times 10^{4} \mathrm{TCID}_{50}$ VSV-WT (each, $\left.n=8\right)$ or PBS ( $n=$ 8 ), respectively. Mice were monitored for signs of neurotoxicity over a period of 40 days (Fig. 6a). Two mice of the high-dose srVSV group were sacrificed at $3 \mathrm{dpi}$, and in vivo copropagation was found to be restricted to the needle track and its proximity by immunofluorescence analysis (Fig. 6b). Most importantly, none of the $\operatorname{srVSV}(\Delta \mathrm{G} / \Delta \mathrm{L})$-injected animals showed any evidence of neuropathology with $100 \%$ of animals surviving to the end point as did the PBS-injected negative control cohort. In striking contrast, both the lowand high-dose VSV-WT cohort developed neuropathology within 2-9 dpi with all mice succumbing to neurological
Fig. 5 srVSV shows

copropagation in vivo leading to antitumor activity without adverse effects. NOD/SCID mice were subcutaneously transplanted with $10^{6} \mathrm{G} 62$ human glioblastoma cells per flank. At a tumor size of approximately $0.1 \mathrm{~cm}^{3}$, tumors were either treated with PBS, $2.8 \times 10^{5} \mathrm{TCID}_{50}$ VSV-WT or $2.8 \times 10^{5} \mathrm{TCID}_{50} \operatorname{srVSV}(\Delta \mathrm{G} /$ $\Delta \mathrm{L})$. a Tumor growth was assessed with a caliper. Mice with tumors exceeding $0.8 \mathrm{~cm}^{3}$ were sacrificed. b Two representative srVSV-treated mice were sacrificed at $3 \mathrm{dpi}$, tumors were removed and suspended in PBS/4\% paraformaldehyde. Tumor sections $(40 \mu \mathrm{m})$ were prepared and nuclear counterstaining was performed with TO-PRO-3 iodide. c Kaplan-Meier survival analysis of the respective treatment groups. ${ }^{* *} p<0.01,{ }^{* * *} p<$ 0.001 . i.t. intratumoral, arrow injection site
A
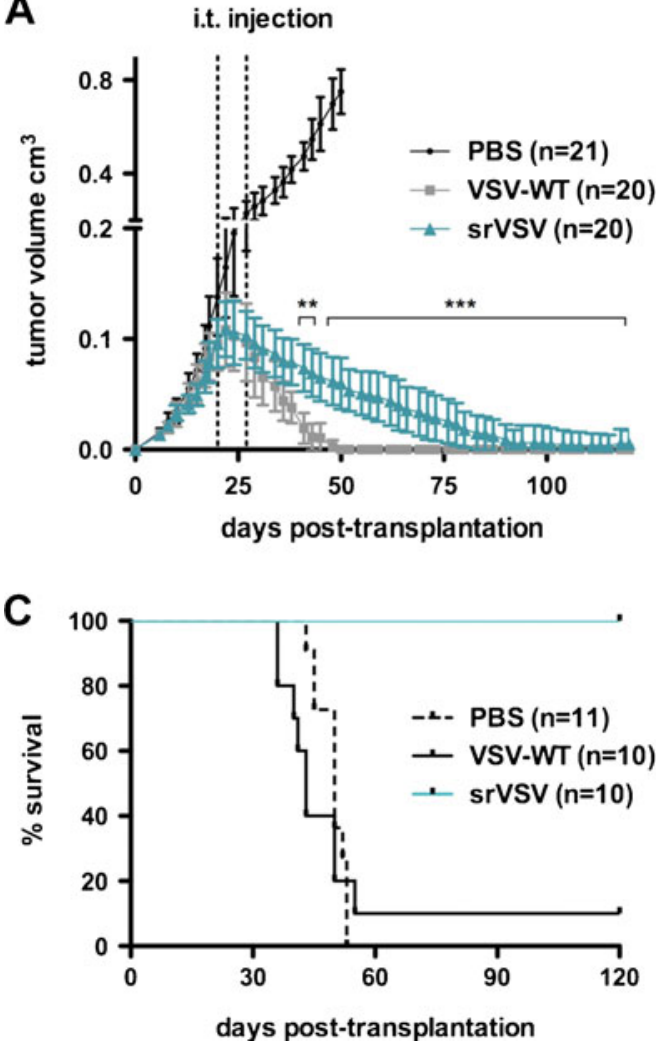

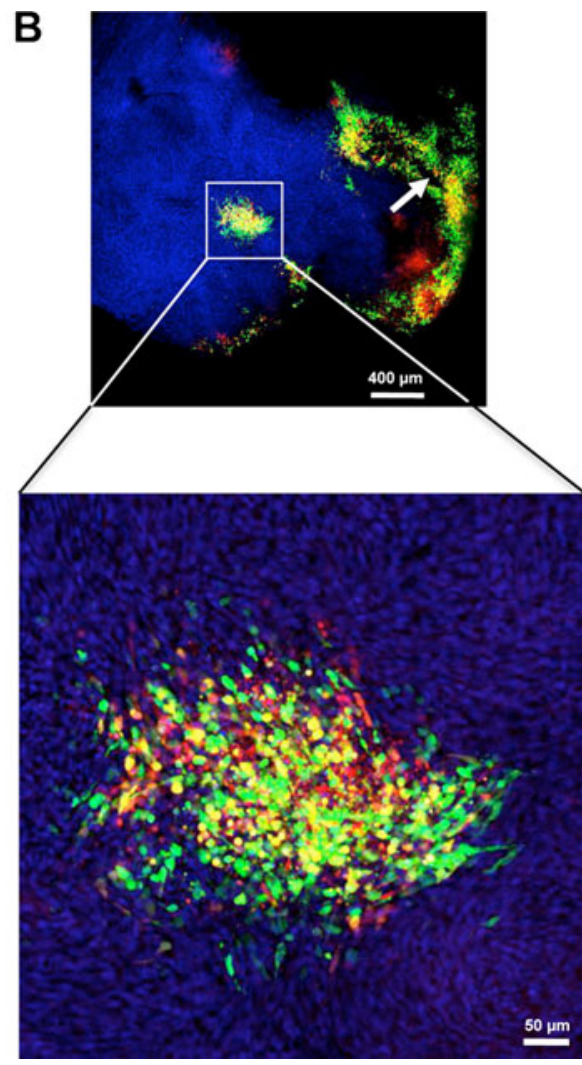




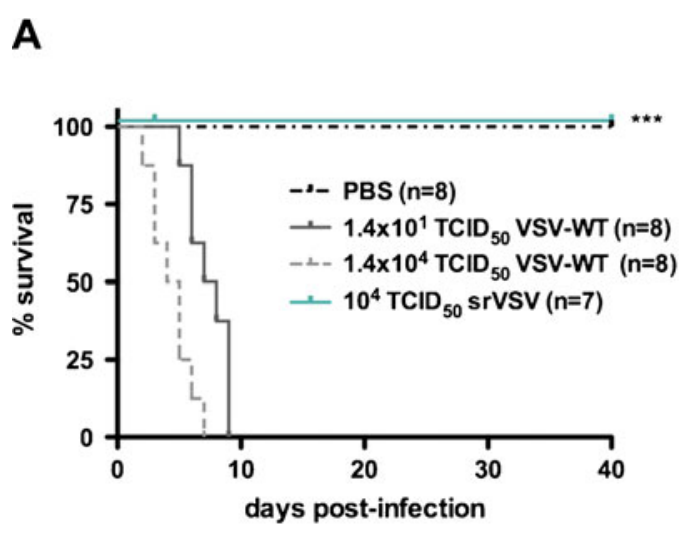

Fig. 6 srVSV exhibits reduced neurotoxicity relative to VSV-WT. Escalating doses of $10^{2}, 10^{3}$, and $10^{4} \operatorname{TCID}_{50} \operatorname{srVSV}(\Delta \mathrm{G} / \Delta \mathrm{L})$ as well as $1.4 \times 10^{1}$ and $1.4 \times 10^{4} \mathrm{TCID}_{50}$ VSV-WT or PBS were stereotactically injected into mouse brains. a Animals were monitored for signs of neurological impairment for 40 days. As all srVSV-treated cohorts showed event-free survival up to the end point, only the data set of the

symptoms by day 9 and a median survival of 4.5 dpi (1.4× $10^{4} \mathrm{TCID}_{50}$ VSV-WT $)$ and $7.5 \mathrm{dpi}\left(1.4 \times 10^{1} \mathrm{TCID}_{50} \mathrm{VSV}-\right.$ WT), respectively. Hence, neurotoxicity of $\operatorname{srVSV}(\Delta \mathrm{G} / \Delta \mathrm{L})$ was at least $>700$-fold reduced if compared to VSV-WT with differences in survival between srVSV- and VSVWT-treated cohorts being highly significant $(p<0.001)$.

$\operatorname{srVSV}(\Delta G / \Delta L)$ is a potent type I IFN inducer As it was previously shown that type I IFN-inducing strains of VSV were strongly attenuated regarding their toxicity [26], the capacity of $\operatorname{srVSV}(\Delta \mathrm{G} / \Delta \mathrm{L})$ to induce IFN was evaluated in murine pDC cultures. pDCs were infected with either $\operatorname{srVSV}(\Delta \mathrm{G} / \Delta \mathrm{L}), \mathrm{VSV}^{*} \Delta \mathrm{G}, \mathrm{VSV} \Delta \mathrm{L}$-DsRed, or VSV-WT as negative and $\mathrm{VSV}^{*} \mathrm{M}_{\mathrm{Q}}$ as positive control at an MOI of 2 . Culture supernatants were collected at $24 \mathrm{hpi}$ and analyzed for IFN- $\alpha$ via ELISA. Unsurprisingly, the VSV-M multimutated positive control $\mathrm{VSV}^{*} \mathrm{M}_{\mathrm{Q}}$ induced the strongest type I IFN response, with $3,200.11 \pm 57.02 \mathrm{pg}$ IFN- $\alpha$ per $\mathrm{ml}$ supernatant, whereas VSV-WT treatment induced 18-fold lower amounts $(174.47 \pm 16.70 \mathrm{pg} / \mathrm{ml} ; p<0.0001)$, being consistent with Waibler et al. [22]. In striking contrast to VSVWT, $\operatorname{srVSV}(\Delta \mathrm{G} / \Delta \mathrm{L})$ proved to be a very potent type I IFN inducer with significantly elevated IFN- $\alpha$ levels of $1,035.52 \pm$ $50.57 \mathrm{pg} / \mathrm{ml}(p<0.0001)$. However, single-vector treatment with propagation-deficient $\mathrm{VSV}^{*} \Delta \mathrm{G}$ and VSV $\Delta \mathrm{L}$-DsRed induced only basal IFN- $\alpha$ levels.

\section{Discussion}

Here, we developed a semireplication-competent VSV vector system composed of two separate propagation-incompetent viral vectors that shows significant anticancer activity without the neurotoxicity usually found in VSV infection of mice and high-dose srVSV-treated cohort is shown. b Two mice of the $10^{4}$ $\operatorname{TCID}_{50} \operatorname{srVSV}(\Delta \mathrm{G} / \Delta \mathrm{L})$-treated group were sacrificed at $3 \mathrm{dpi}$, brains were fixed and sections $(40 \mu \mathrm{m})$ prepared for immunofluorescence analysis. Nuclear counterstaining was performed with TO-PRO-3 iodide. ${ }^{* *} p<0.001$, arrow injection site

nonhuman primates. Three different vector pairs of three separate propagation-incompetent vectors VSV $\Delta \mathrm{P}$-DsRed, $\mathrm{VSV}^{*} \Delta \mathrm{G}$, and VSV $\Delta \mathrm{L}$-DsRed were feasible, and all three combinations were able to effectively trans-complement each other and generate progeny virions (Figs. 1b, c and 2 and Table 1).

The combination of $\mathrm{VSV}^{*} \Delta \mathrm{G}$ and VSV $\Delta \mathrm{L}$-DsRed proved to be the most potent in terms of vector propagation (Fig. 1b, Table 1) and in vitro antitumor efficacy (Fig. 4), being only slightly attenuated compared to VSV-WT. That this combination outperforms the other srVSV systems is most likely due to the small genome size of the VSV-L gene deleted VSV $\Delta$ L-DsRed vector (5.6 kB, Fig. 1a). Compared to full-length VSV, the smaller sized VSV $\Delta \mathrm{L}$-DsRed genome is statistically favored for replication, packaging, and viral shedding. This is consistent with VSV-defective interfering particles, as apart from the $5^{\prime}-3^{\prime}$ terminal complementarity as major determinant, genome size was also shown to impact their replicative dominance over VSV-WT [15, 27]. Moreover, the asymmetric contributions of either vector genome and particularly the overrepresentation of VSV $\Delta$ L-DsRed in the $\operatorname{srVSV}(\Delta \mathrm{G} / \Delta \mathrm{L})$ and the $\operatorname{rrVSV}(\Delta \mathrm{P} / \Delta \mathrm{L})$ system (Fig. 1c) as well as the fact that both VSV $\Delta$ L-DsRed containing srVSV systems exhibit superior antitumor efficacy compared to $\operatorname{srVSV}(\Delta \mathrm{P} / \Delta \mathrm{G})$ (Fig. 4) can also be explained by the genome size-dependent replicative advantage. In fact, despite the low initial MOI of 0.2 , coamplification led to a nearly complete tumor cell killing in vitro at $96 \mathrm{hpi}$ for glioma monolayer and spheroid cultures, underscoring the strong oncolytic potential of both $\operatorname{srVSV}(\Delta \mathrm{G} / \Delta \mathrm{L})$ and $\operatorname{srVSV}(\Delta \mathrm{P} / \Delta \mathrm{L})$. However, compared to $\operatorname{srVSV}(\Delta \mathrm{P} / \Delta \mathrm{L})$, the $(\Delta \mathrm{G} / \Delta \mathrm{L})$ combination proved to be somewhat more potent in terms of vector propagation. The $\mathrm{VSV}^{*} \Delta \mathrm{G}$ vector, which lacks the ability to produce infectious virus but still exhibits functional replication and 
transcription, provides the L polymerase for immediate VSV $\Delta$ L-DsRed replication and transcription upon coinfection. This is opposed to $\operatorname{srVSV}(\Delta \mathrm{P} / \Delta \mathrm{L})$, as here only double-infected cells support efficient genome replication and transcription, which might explain for the marginal reduced replication competence of the latter system. Accordingly, the most potent $\operatorname{srVSV}$ system, $\operatorname{srVSV}(\Delta \mathrm{G} / \Delta \mathrm{L})$, was assessed for its antitumor potency in a s.c. G62 human glioblastoma xenograft model. All srVSV-treated tumors showed a clear response starting at 2 dpi. Tumors regressed and viral dissemination could be detected throughout the neoplastic tissue by immunohistochemistry (Fig. 5a, b). Although, compared to VSVWT-treated mice tumor regression was significantly slower, srVSV treatment was not associated with any severe adverse effects (Fig. 5c). Whereas $90 \%$ of mostly $(70 \%)$ tumor-free VSV-WT-treated animals had to be euthanized due to neurotoxicity, srVSV treatment resulted in long-term survival of all animals with $80 \%$ tumor clearance at $100 \mathrm{dpt}$ compared to both control cohorts. Thus, it can be assumed that replication of srVSV is self-contained to the injection site and adjacent areas of the topically treated tumor, reducing the risk of a systemic infection or dissemination.

On the other hand, this intrinsic safety of binary srVSV systems may reduce therapeutic efficacy upon systemic application, as cells within target tissue need to be double infected to trigger oncolytic copropagation in the tumor. However, when delivered locoregionally, the srVSV system indeed exhibits a vastly improved therapeutic index when compared to VSV-WT, as even after direct intracerebral administration of escalating viral doses into mouse brains no toxicity could be observed. All srVSV-treated mice (lowand high-dose cohorts) showed $100 \%$ event-free survival up to the end point of the study (40 days, Fig. 6a). Again, immunohistochemistry of mice sacrificed at 3 dpi displayed locally restricted srVSV copropagation at the needle track and its close proximity (Fig. 6b). In contrast, both low- and high-dose cohorts of VSV-WT-treated mice developed neurotoxicity with a median survival of $7.5 \mathrm{dpi}\left(1.4 \times 10^{1} \mathrm{TCID}_{50}\right)$ or even 4.5 dpi for the high-dose cohort $\left(1.4 \times 10^{4} \mathrm{TCID}_{50}\right.$, Fig. $\left.6 \mathrm{a}\right)$. Hence, in direct comparison with VSV-WT, the srVSVassociated neurotoxicity is at least $>700$-fold reduced while retaining its potent oncolytic activity.

As infection of susceptible cells for both viral systems, VSV-WT and srVSV, is mediated by the VSV-G envelope protein, the attenuated phenotype of srVSV is not due to a shift of tropism. Instead, our data emphasize two aspects, which lead to a general and a more specific attenuation: First, the srVSV intrinsic mode of replication leads to a general attenuation per se, as copropagation is limited to foci of high vector concentrations resulting in doubleinfected cells and ongoing spread. At distal sites to the replicating foci, vector concentrations dramatically decrease particularly in solid tissue possibly ending off copropagation.
Consistently, discrete foci of copropagation could be observed throughout the tumor diameter in intratumoral injected s.c. tumors (Fig. 5b) as well as in mouse brains after intracranial injection (Fig. 6b). Second, srVSV proved to be a very potent type I IFN inducer, inducing at least 18 -fold higher IFN- $\alpha$ amounts when compared to VSV-WT (Fig. 7). Similar to the IFN-inducing VSV strains AV1 and AV2, we expect srVSV to be selectively attenuated in IFN-responsive, healthy cells while retaining its lytic potential in IFN-deregulated neoplastic cells. However, in comparison with AV1 and AV2, the ability to induce type I IFN is not attributed to a mutant VSV-M, which blocks host nucleocytoplasmic mRNA export, as both components of the binary system code for wild-type VSV-M [26]. In this regard we presume that due to the gene deletions, the $\operatorname{srVSV}(\Delta \mathrm{G} / \Delta \mathrm{L})$ coreplication operates on a distorted transcription gradient with deficient levels of VSV-G and VSV-L particularly in the initial phase postinfection. These aberrant VSV protein levels may potentially lead to a prolonged retention time of unassembled virions within the host cell with the prolonged residence of viral RNA eventually triggering pattern recognition receptors, which can initiate a type I IFN response. The exact reason for the IFN-inducing capability of srVSV as well as its contribution to the overall attenuation of srVSV clearly requires further analysis.

In addition, the srVSV systems were also safe with respect to potential recombinatory reversion to a replicationcompetent phenotype, as after 20 consecutive passages at limiting dilutions, phenotypic and genotypic analyses were negative for recombinant replication-competent virus, with VSV-WT spiked positive controls validating the assays (Fig. 3). This observation is also consistent with earlier studies on the potential recombination between temperature-sensitive VSV mutants [28].

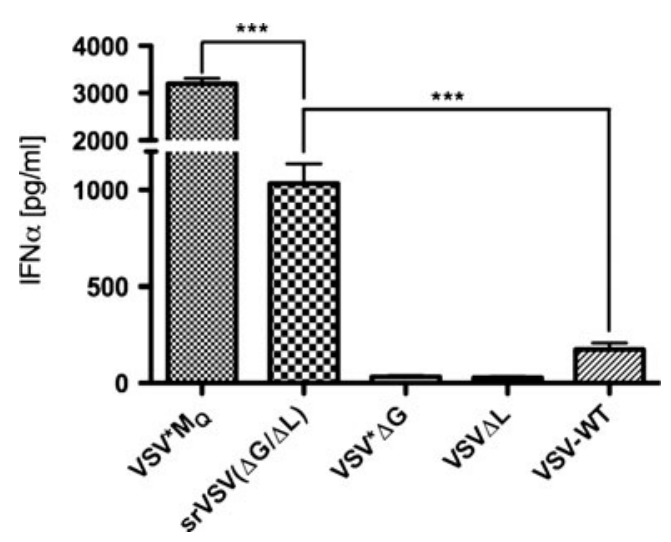

Fig. $7 \mathrm{srVSV}$ is a potent type I IFN inducer. Mouse plasmacytoid DC cultures were infected at an MOI of 2 with either $\operatorname{srVSV}(\Delta \mathrm{G} / \Delta \mathrm{L})$, $\mathrm{VSV}^{*} \Delta \mathrm{G}$, VSV $\Delta \mathrm{L}$-DsRed, VSV-WT, or the strongly type I IFNinducing $\mathrm{VSV}^{*} \mathrm{M}_{\mathrm{Q}}$ as a positive control (each $n=2$ ). Culture supernatants were collected at $24 \mathrm{hpi}$ and analyzed for IFN- $\alpha$ via ELISA 
In summary, relative to VSV-WT, srVSV systems present a promising platform for virotherapeutic approaches, as they are genetically stable and exhibit considerably reduced neurotoxicity while retaining their antitumor potency. Furthermore, srVSV systems offer a strongly increased coding capacity so that both viral vectors can be "armed" to express therapeutic transgenes allowing for multipronged approaches, combining their inherent oncolytic effect with a tumor microenvironment modulating suicide and/or immunostimulatory "payload" to boost antitumor potency. Eventually, with respect to both biosafety and coding capacity, srVSV systems may not only prove valuable for oncolytic virotherapy but also represent an attractive vector vaccine platform.

Acknowledgments This work was supported by grants from the Wilhelm-Sander-Foundation and the Schering foundation Deutsche Forschungsgemeinschaft (Graduate College 1172). We thank Stefan Momma and Anna Kraft for CLSM assistance.

Disclosure of potential conflict of interests The authors declare no conflict of interests related to this study.

Open Access This article is distributed under the terms of the Creative Commons Attribution License which permits any use, distribution, and reproduction in any medium, provided the original author(s) and the source are credited.

\section{References}

1. Alain T, Lun X, Martineau Y, Sean P, Pulendran B, Petroulakis E, Zemp FJ, Lemay CG, Roy D, Bell JC et al (2010) Vesicular stomatitis virus oncolysis is potentiated by impairing mTORC1dependent type I IFN production. Proc Natl Acad Sci USA 107:1576-1581

2. Wollmann G, Rogulin V, Simon I, Rose JK, van den Pol AN (2010) Some attenuated variants of vesicular stomatitis virus show enhanced oncolytic activity against human glioblastoma cells relative to normal brain cells. J Virol 84:1563-1573

3. Shinozaki K, Ebert O, Woo SL (2005) Eradication of advanced hepatocellular carcinoma in rats via repeated hepatic arterial infusions of recombinant VSV. Hepatology 41:196-203

4. Ebert O, Shinozaki K, Huang TG, Savontaus MJ, Garcia-Sastre A, Woo SL (2003) Oncolytic vesicular stomatitis virus for treatment of orthotopic hepatocellular carcinoma in immune-competent rats. Cancer Res 63:3605-3611

5. Ahmed M, Cramer SD, Lyles DS (2004) Sensitivity of prostate tumors to wild type and $\mathrm{M}$ protein mutant vesicular stomatitis viruses. Virology 330:34-49

6. Moussavi M, Fazli L, Tearle H, Guo Y, Cox M, Bell J, Ong C, Jia W, Rennie PS (2010) Oncolysis of prostate cancers induced by vesicular stomatitis virus in PTEN knockout mice. Cancer Res 70:1367-1376

7. Capo-chichi CD, Yeasky TM, Heiber JF, Wang Y, Barber GN, Xu XX (2010) Explicit targeting of transformed cells by VSV in ovarian epithelial tumor-bearing Wv mouse models. Gynecol Oncol 116:269-275
8. Huneycutt BS, Bi Z, Aoki CJ, Reiss CS (1993) Central neuropathogenesis of vesicular stomatitis virus infection of immunodeficient mice. J Virol 67:6698-6706

9. Johnson JE, Nasar F, Coleman JW, Price RE, Javadian A, Draper K, Lee M, Reilly PA, Clarke DK, Hendry RM et al (2007) Neurovirulence properties of recombinant vesicular stomatitis virus vectors in non-human primates. Virology 360:36-49

10. Clarke DK, Nasar F, Lee M, Johnson JE, Wright K, Calderon P, Guo M, Natuk R, Cooper D, Hendry RM et al (2007) Synergistic attenuation of vesicular stomatitis virus by combination of specific G gene truncations and N gene translocations. J Virol 81:20562064

11. Kelly EJ, Nace R, Barber GN, Russell SJ (2010) Attenuation of vesicular stomatitis virus encephalitis through microRNA targeting. J Virol 84:1550-1562

12. Duntsch CD, Zhou Q, Jayakar HR, Weimar JD, Robertson JH, Pfeffer LM, Wang L, Xiang Z, Whitt MA (2004) Recombinant vesicular stomatitis virus vectors as oncolytic agents in the treatment of high-grade gliomas in an organotypic brain tissue slice-glioma coculture model. J Neurosurg 100:1049-1059

13. Alemany R, Lai S, Lou YC, Jan HY, Fang X, Zhang WW (1999) Complementary adenoviral vectors for oncolysis. Cancer Gene Ther 6:21-25

14. Trajcevski S, Solly SK, Frisen C, Trenado A, Cosset FL, Klatzmann D (2005) Characterization of a semi-replicative gene delivery system allowing propagation of complementary defective retroviral vectors. J Gene Med 7:276-287

15. Wagner RR, Rose JK (1996) Rhabdoviridae: the viruses and their replication. In: Whitley BNF RJ, Knipe DM, Howley PM (eds) Fields virology, 3rd edn. Lippincott-Raven Publishers, Philadelphia

16. Hanika A, Larisch B, Steinmann E, Schwegmann-Wessels C, Herrler G, Zimmer G (2005) Use of influenza C virus glycoprotein HEF for generation of vesicular stomatitis virus pseudotypes. J Gen Virol 86:1455-1465

17. Panda D, Dinh PX, Beura LK, Pattnaik AK (2010) Induction of interferon and interferon signaling pathways by replication of defective interfering particle RNA in cells constitutively expressing vesicular stomatitis virus replication proteins. J Virol 84:48264831

18. Hoffmann M, Wu YJ, Gerber M, Berger-Rentsch M, Heimrich B, Schwemmle M, Zimmer G (2010) Fusion-active glycoprotein G mediates the cytotoxicity of vesicular stomatitis virus $M$ mutants lacking host shut-off activity. J Gen Virol 91:2782-2793

19. Ebert O, Shinozaki K, Kournioti C, Park MS, Garcia-Sastre A, Woo SL (2004) Syncytia induction enhances the oncolytic potential of vesicular stomatitis virus in virotherapy for cancer. Cancer Res 64:3265-3270

20. Muik A, Kneiske I, Werbizki M, Wilflingseder D, Giroglou T, Ebert O, Kraft A, Dietrich U, Zimmer G, Momma S et al (2011) Pseudotyping vesicular stomatitis virus with lymphocytic choriomeningitis virus glycoproteins enhances infectivity for glioma cells and minimizes neurotropism. J Virol 85:5679-5684

21. Kärber G (1931) 50\% end-point calculation. Arch Exp Pathol Pharmak 162:480-483

22. Waibler Z, Detje CN, Bell JC, Kalinke U (2007) Matrix protein mediated shutdown of host cell metabolism limits vesicular stomatitis virus-induced interferon-alpha responses to plasmacytoid dendritic cells. Immunobiology 212:887-894

23. Taucher C, Berger A, Mandl CW (2010) A trans-complementing recombination trap demonstrates a low propensity of flaviviruses for intermolecular recombination. J Virol 84:599-611

24. Sutherland RM (1988) Cell and environment interactions in tumor microregions: the multicell spheroid model. Science 240:177-184

25. Tamaki M, McDonald W, Amberger VR, Moore E, Del Maestro RF (1997) Implantation of C6 astrocytoma spheroid into collagen type I 
gels: invasive, proliferative, and enzymatic characterizations. J Neurosurg 87:602-609

26. Stojdl DF, Lichty BD, tenOever BR, Paterson JM, Power AT, Knowles S, Marius R, Reynard J, Poliquin L, Atkins H et al (2003) VSV strains with defects in their ability to shutdown innate immunity are potent systemic anti-cancer agents. Cancer Cell $4: 263-275$
27. Von Laer DM, Mack D, Kruppa J (1988) Delayed formation of defective interfering particles in vesicular stomatitis virus-infected cells: kinetic studies of viral protein and RNA synthesis during autointerference. J Virol 62:1323-1329

28. Wong PK, Holloway AF, Cormack DV (1971) A search for recombination between temperature-sensitive mutants of vesicular stomatitis virus. J Gen Virol 13:477-479 